\title{
Control of a Flyback Converter in Mixed Conduction Mode: Influence on the Converter Design Using Optimization under Constraints
}

\author{
Cherif Larouci $^{* a)} \quad$ Non-member, Toufik Azib* Non-member \\ Ahmed Chaibet ${ }^{*}$ Non-member, Moussa Boukhnifer* Non-member
}

(Manuscript received Feb. 25, 2012, revised April 18, 2012)

\begin{abstract}
This paper deals with the control of a flyback converter in power factor correction (PFC) mode and the influence of the conduction mode on the converter design when using an optimization under constraints approach. In this context, a mixed control associated with mixed current conduction combining both discontinuous and continuous conduction over the low frequency period is presented, simulated and validated by experiments. This mixed conduction, which allows a compromise between transformer volume and semiconductor current constraints (maximal and RMS current values), is integrated within a flyback design approach using optimization under constraints. The obtained results demonstrate the effectiveness of this optimization approach in determining the balance between discontinuous and continuous conduction durations over the low frequency period. Moreover, the interest to consider the conduction mode as an optimization criterion is established.
\end{abstract}

Keywords: power converters design, flyback converter, control in mixed conduction, design using optimization under constraints

\section{Introduction}

This paper presents a control study of a flyback converter operating in power factor correction (PFC) mode and the impact of the current conduction mode on this converter design. In fact, an analysis of the flyback structure presented in figure 1 shows two main conduction modes: discontinuous conduction and continuous one. The current constraints are more significant in discontinuous conduction than in continuous conduction. Conversely, the magnetic circuit volume of the flyback transformer in continuous conduction can be several times higher than in discontinuous conduction at a same transmitted power and a same switching frequency ${ }^{(1)-(3)}$.

To take advantage of each conduction mode and make compromise between the transformer volume and the semiconductor current constraints, a mixed control is proposed in this paper where the two modes, continuous and discontinuous, appear during the low frequency period.

Moreover, several research activities have been devoted to the design and the control of flyback structures ${ }^{(4)-(7)}$. Most of these works focus on the design aspect without consideration of control or deal with the control aspect after a design step.

Other works have studied coupling between control and some design criteria but without consideration of the whole constraints within a global design approach ${ }^{(8)-(10)}$.

In this context, a generic power converters design methodology using optimization under constraints has been developed $^{(11)}$. In the current paper, the mixed conduction is considered as a key optimization parameter when designing the

a) Correspondence to: Cherif Larouci. E-mail: cherif.larouci@ estaca.fr

* Control and System laboratory, ESTACA Engineering School

34 rue Victor Hugo, 92300 Levallois Perret, France flyback converter using this optimization approach. The aim is to consider the control aspect associated to this mixed conduction with the same importance as the conventional design constraints (volume, efficiency, electromagnetic compatibility $(\mathrm{EMC}), \ldots$ ) and therefore to evaluate its influence on the converter design.

This paper is organized as follows: the studied structure is presented in section 2. An analysis in discontinuous and continuous conductions is carried out in section 3. In section 4 , control strategies associated to discontinuous and mixed conductions are developed, simulated and validated by experiments. Finally, the mixed conduction is integrated in an optimization under multi-physics constraints approach. The main design results of the flyback converter are given and discussed in section 5 .

\section{Flyback Studied Structure}

Figure 1 shows an AC/DC-DC flyback structure used in mono-stage converter to ensure sinusoidal input current and output voltage regulation. It has the advantages of a monoswitch structure, easily to control and including few components ${ }^{(12)-(16)}$. In addition, it offers a galvanic insulation and

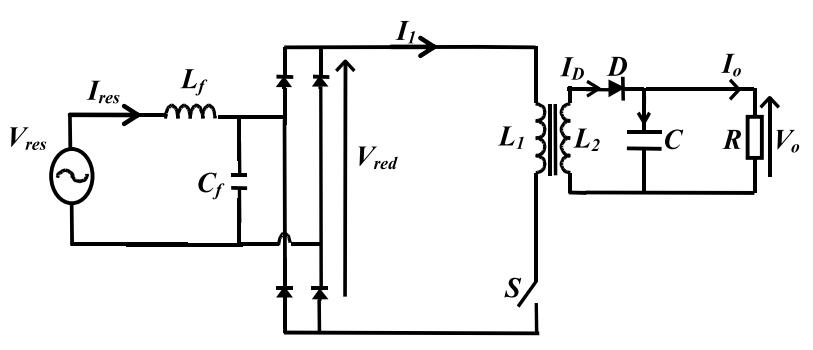

Fig. 1. A flyback structure 
allows low output voltage thanks to the transformation ratio of the transformer ${ }^{(17)-(19)}$.

\section{Analysis in Discontinuous and Continuous Conductions}

This structure is characterized by two-time-scales:

- a low frequency period related to the AC network of voltage $V_{\text {res }}(t)=V_{\text {max }} \cdot \sin \left(2 \cdot \pi \cdot F_{r} \cdot t\right)$ of amplitude $\mathrm{V}_{\max }$ and frequency $\mathrm{F}_{\mathrm{r}}$.

- a high frequency period related to the converter switching frequency $\mathrm{F}_{\mathrm{s}}$.

3.1 Analysis on High Frequency Period Over a high frequency period, the voltage $V_{\text {red }}(t)=V_{\max } \cdot\left|\sin \left(2 \cdot \pi \cdot F_{r} \cdot t\right)\right|$ (figure 1) can be considered constant (of value $\mathrm{V}_{\text {red }}$ ).

Under this assumption, the perfect switch and diode currents waveforms during continuous conduction (cc) and discontinuous conduction (dc) are given in figure 2 .

We can deduce in this case formulas of the primary current $I_{1}$ (current in the switch $S$ ) and secondary current $I_{D}$ (current in the diode $\mathrm{D}$ ) on a high frequency period in discontinuous conduction (1), (2):

$$
\begin{aligned}
& I_{1}(t)=\frac{V_{r e d}}{L_{1}} \cdot t \ldots \ldots \ldots \ldots \ldots \ldots \ldots \ldots \\
& I_{D}(t)=-\frac{V_{o}}{L_{2}} \cdot\left(t-\alpha \cdot T_{s}\right)+\frac{I_{1 \max }}{m}
\end{aligned}
$$

Where:

$\mathrm{L}_{1}$ and $\mathrm{L}_{2}$ : the primary and secondary inductances,

$\mathrm{V}_{\mathrm{o}}$ : the output voltage value,

$\mathrm{T}_{\mathrm{s}}=1 / \mathrm{F}_{\mathrm{s}}$ : the switching period,

$\mathrm{F}_{\mathrm{s}}$ : the switching frequency,

$\mathrm{m}=\mathrm{n} 2 / \mathrm{n} 1$ : the transformer transformation ratio,

$\mathrm{n} 1$ and $\mathrm{n} 2$ : number of turns of the primary and secondary windings

$\alpha$ : the duty cycle.

$I_{1 \max }$ : the maximal value of the current $I_{1}$. This value is obtained from (1) at $\mathrm{t}=\alpha$. Ts:

$$
I_{1 \text { max }}=\frac{V_{\text {red }}}{L_{1}} \cdot \alpha \cdot T_{S}
$$

The mean value of the primary current $\mathrm{I}_{1}$ (triangle area in figure 2(b)) is given by:

$$
I_{1 \text { mean }}=\frac{1}{2} \cdot \alpha \cdot I_{1 \text { max }}=\frac{\alpha^{2} \cdot V_{\text {red }}}{2 \cdot L_{1} \cdot F_{S}} .
$$

In this case, the transmitted power $\mathrm{P}_{\mathrm{o}}$ can be expressed as follows:

$$
P_{o}=V_{\text {red }} \cdot I_{1 \text { mean }}=\frac{\alpha^{2} \cdot V_{r e d}^{2}}{2 \cdot L_{1} \cdot F_{s}}
$$

According to figure 2(b) and knowing that $\mathrm{L}_{2}=\mathrm{m}^{2} \cdot \mathrm{L}_{1}$, the diode duration conduction $[(\beta-\alpha) \cdot \mathrm{Ts}]$ can be expressed from (2) as follows:

$$
(\beta-\alpha) \cdot T_{s}=\frac{m \cdot V_{r e d} \cdot \alpha \cdot T_{s}}{V_{o}}
$$

The duration $[(1-\beta) \cdot \mathrm{Ts}]$ of the zero current phase is than deduced from (6) as follows:

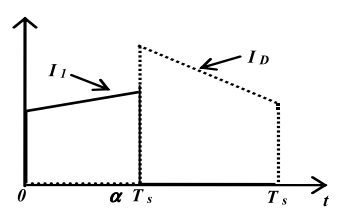

(a)

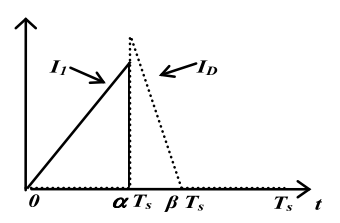

(b)
Fig. 2. Currents waveforms in continuous and discontinuous conductions

$$
(1-\beta) \cdot T_{s}=\left[1-\alpha \cdot\left(1+\frac{m \cdot V_{\text {red }}}{V_{o}}\right)\right] \cdot T_{s} \cdots \cdots \cdots
$$

From (7) and by imposing $\beta=1$, we can deduce a duty cycle limit value allowing to work at the limit between discontinuous and continuous conductions (8):

$$
\alpha_{\text {limit }}=\frac{V_{o}}{V_{o}+m \cdot V_{\text {red }}}
$$

3.2 Analysis on the Low Frequency Period Over the low frequency period, the voltage $V_{\text {red }}$ (figure 1) has the following expression:

$$
V_{\text {red }}(t)=V_{\text {max }} \cdot\left|\sin \left(2 \cdot \pi \cdot F_{r} \cdot t\right)\right| \cdots
$$

From (5) and knowing $\mathrm{V}_{\text {red }}(\mathrm{t})$, we can deduce the transmitted power variations (in discontinuous conduction) over the low frequency period (10):

$$
d P_{o}=\frac{\alpha^{2} \cdot V_{r e d}^{2}(t)}{2 \cdot L_{1} \cdot F_{s}} \cdot d t
$$

After integration over the low frequency period $T_{r}$, the transmitted power $\mathrm{P}_{\mathrm{o}}$ in discontinuous conduction can be expressed as follows:

$$
P_{o}=\frac{\alpha^{2} \cdot V_{\max }^{2}}{4 \cdot L_{1} \cdot F_{s}}=\frac{V_{o}^{2}}{R}
$$

$\mathrm{R}$ is the output resistance modeling the converter load.

From (8) and considering the critical case for which $\max \left(\mathrm{V}_{\text {red }}\right)=\mathrm{V}_{\max }$, we can deduce a duty cycle limit value allowing a discontinuous conduction over all the low frequency period (12):

$$
\alpha_{\text {limit }}=\frac{V_{o}}{V_{o}+m \cdot V_{\max }}
$$

To ensure discontinuous conduction over the whole low frequency period, the duty cycle $\alpha$ in discontinuous conduction calculated from (11) must be lower than $\alpha_{\text {limt }}$ given by (12). Therefore, from (11) and (12) we deduce that discontinuous conduction is ensured over the whole low frequency period if the transformer magnetizing inductance $\mathrm{L}_{\mathrm{m}}$ (supposed equal to $\mathrm{L}_{1}$ ) checks the following relation:

$$
\frac{4 \cdot F_{s} \cdot L_{m}}{R}<\frac{1}{\left(\frac{V_{o}}{V_{\max }}+m\right)^{2}}
$$

Figure 3 shows the maximal magnetic inductance Lm_max versus frequency (deduced from relation 13) to ensure discontinuous conduction over all the low frequency period. Beyond this limit, the conduction becomes mixed.

Note that at a given load and fixed switching frequency, continuous conduction can be obtained over the whole low 


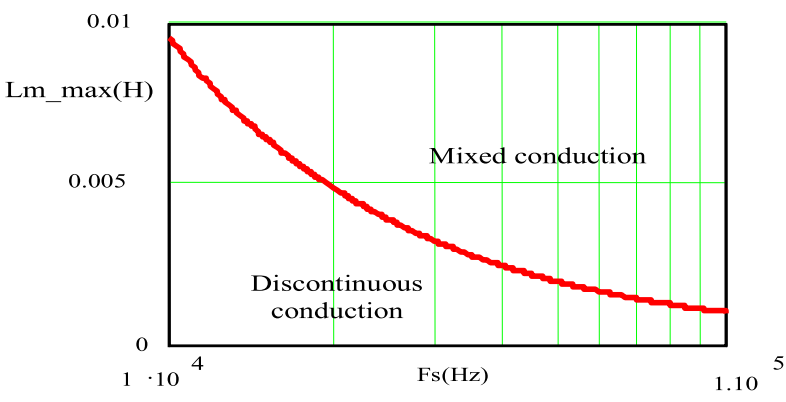

Fig. 3. Maximal magnetic inductance to ensure discontinuous conduction $\left(\mathrm{m}=0.2, \mathrm{P}_{\mathrm{o}}=50 \mathrm{~W}, \mathrm{~V}_{\mathrm{o}}=48 \mathrm{~V}, \mathrm{~V}_{\max }\right.$ $=230 \cdot \sqrt{2} \mathrm{~V}$ )

frequency period but for very high values of the magnetic inductance which induces a very high transformer volume compared to discontinuous and mixed conductions. For this reason, only these two last conductions, more interesting from the point of view design, are considered for simulation and measurement validation in the next section.

\section{Control in PFC Mode}

The aim of the control of the studied flyback converter is to insure sinusoidal input current (PFC mode) whatever the current conduction mode. In this section, control strategies associated to discontinuous and mixed conductions are developed, simulated and validated by measurement results.

4.1 Control Associated to Discontinuous Conduction

As shown in the previous section, the discontinuous conduction needs a low magnetic inductance than the continuous conduction.

From (4) and knowing $\mathrm{V}_{\text {red }}(\mathrm{t})$ from (9), we deduce that the low frequency component of the input current $\mathrm{I}_{1 \text { mean }}(\mathrm{t})$, in discontinuous conduction, is proportional to the input voltage if the duty cycle $\alpha$ and the switching frequency are fixed (14):

$$
I_{1 \text { mean }}(t)=\frac{V_{\text {max }} \cdot \alpha^{2}}{2 \cdot L_{m} \cdot F_{s}} \cdot\left|\sin \left(2 \cdot \pi \cdot F_{r} \cdot t\right)\right| \cdots \cdots \cdots
$$

As a result, sinusoidal input current is ensured naturally in discontinuous conduction by fixing both the switching frequency and the duty cycle.

A. Simulation results in discontinuous conduction

Discontinuous conduction over the low frequency period is ensured by fixing the control parameters values (switching frequency and duty cycle) and choosing a magnetic inductance checking equation 13 .

Figures 4 and 5 show the magnetic current and the output voltage simulated using Pspice software with the following parameters: $\mathrm{F}_{\mathrm{s}}=50 \mathrm{kHz}, \alpha=0.2, \mathrm{~m}=0.5, \mathrm{P}_{\mathrm{o}}=50 \mathrm{~W}, \mathrm{~V}_{\mathrm{o}}=$ $48 \mathrm{~V}, \mathrm{~L}_{\mathrm{m}}=0.5 \mathrm{mH}$, output capacitance $\mathrm{C}=7 \mathrm{mF}$ (designed to ensure $1 \%$ output voltage ripple under $48 \mathrm{~V}$ ).

As expected, and according to the magnetic current waveform, the conduction is discontinuous over the whole low frequency period (AC voltage network). Moreover, the output voltage oscillates around the target value $(48 \mathrm{~V})$ with $1 \%$ ripple.

Figure 6 presents the corresponding filtered input current $\left(\mathrm{I}_{\mathrm{res}}\right)$ using a LC low-pass filter with the following parameters: $\mathrm{L}_{\mathrm{f}}=1.5 \mathrm{mH}$ and $\mathrm{C}_{\mathrm{f}}=0.2 \mu \mathrm{F}$. This filter is designed to attenuate high harmonic frequencies while passing the

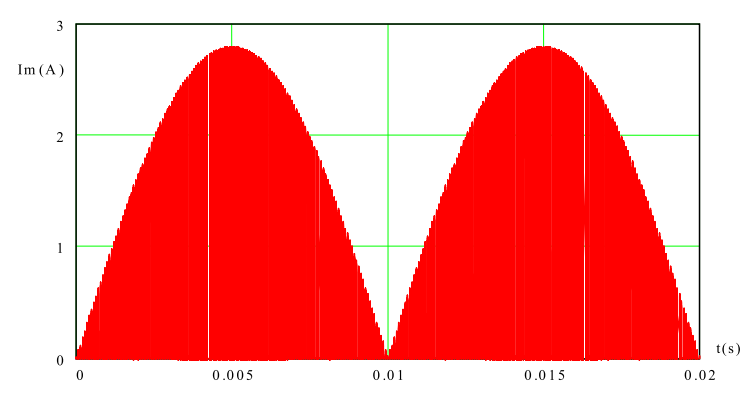

Fig. 4. Magnetic current in discontinuous conduction

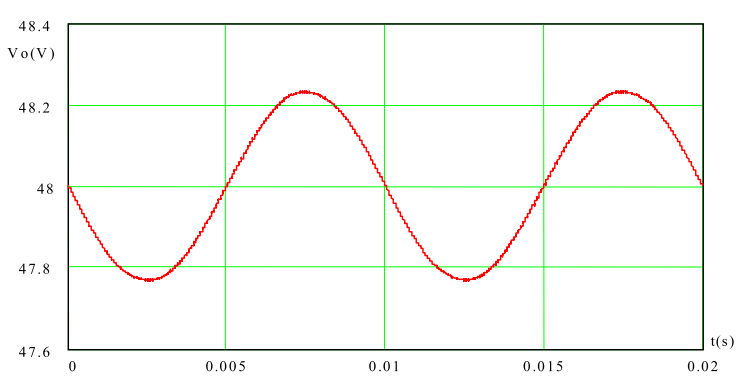

Fig. 5. Output voltage

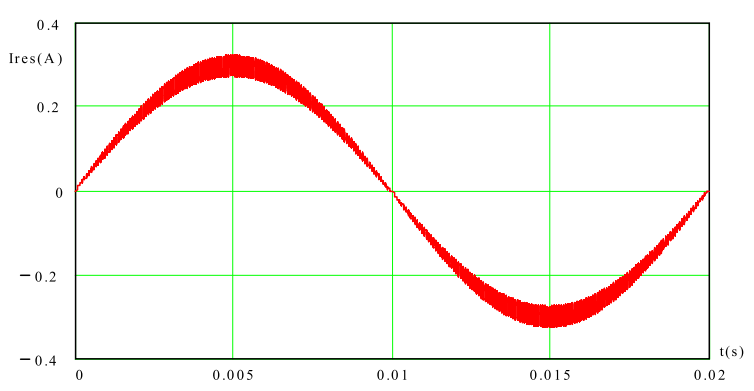

Fig. 6. Input current

fundamental frequency $(50 \mathrm{~Hz})$. To do that, its cut-off frequency is chosen ten times lower than the switching frequency.

According to this figure, the AC network current is sinusoidal which ensure a PFC mode operation.

B. Measurement results in discontinuous conduction

A workbench of the flyback converter in discontinuous conduction has been made considering the converter parameters used in simulation.

Figures 7 and 8 show the measured input current and output voltage:

As result, the input current is sinusoidal and the output voltage oscillates around $48 \mathrm{~V}$ with $1 \%$ ripple which validates the control of the flyback converter in discontinuous conduction.

4.2 Control Associated to Mixed Conduction The mixed conduction combines both discontinuous and continuous conduction on a low frequency period. It consists in controlling the low frequency component of the primary current $I_{1}$ to a sinusoidal reference (figure 9). In this control, the switching frequency is fixed and the duty cycle $\alpha$ is the control parameter which allows the average input current (per switching period) to follow a sinusoidal reference current $\left(\mathrm{I}_{\mathrm{ref}}\right)$.

To carry out this control, the switch $\mathrm{S}$ is turned on at the beginning of each switching period $\left(\mathrm{T}_{\mathrm{s}}\right)$, and turned off when 


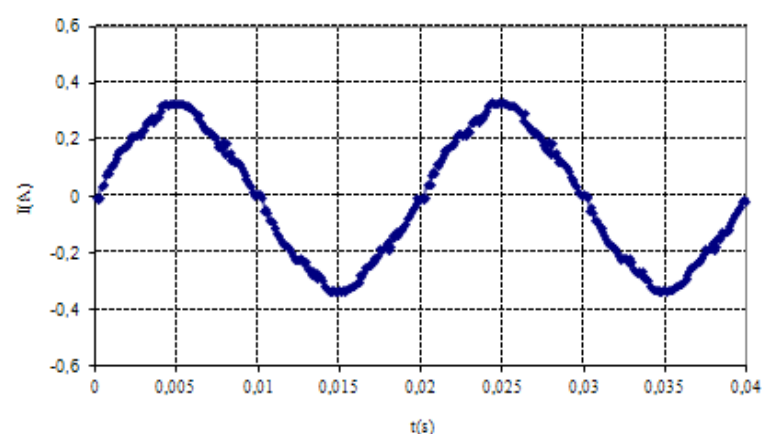

Fig. 7. Input current measurement

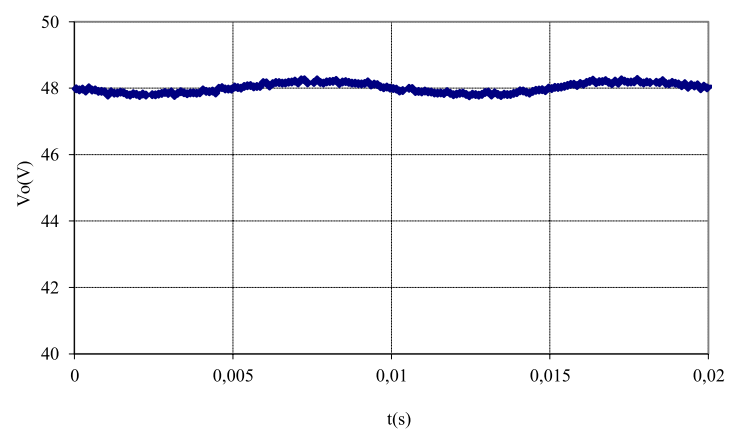

Fig. 8. Output voltage measurement

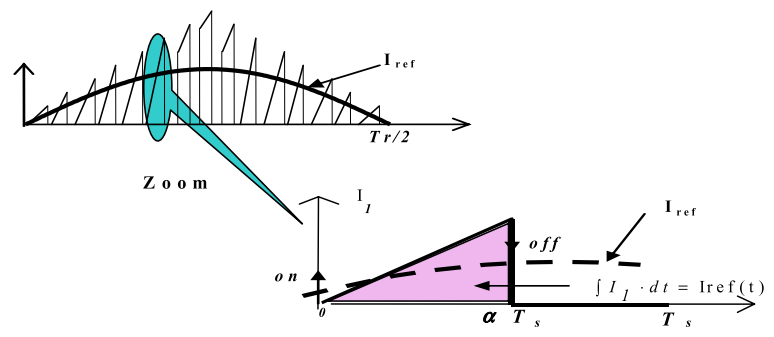

Fig. 9. The mixed control principle

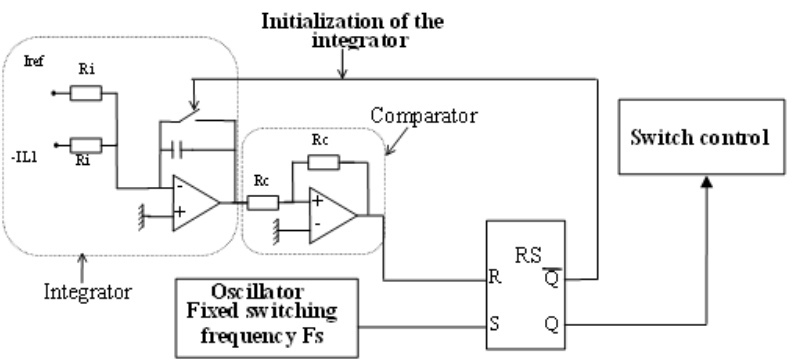

Fig. 10. The mixed control circuit principle

the average current value of the primary inductor over the considered switching period (the triangular surface) becomes equal to the sinusoidal reference.

Figure 10 presents the principle of the mixed control circuit implemented in Pspice software.

The integrator block integrates the difference between the current in the switch $\mathrm{S}$ and the sinusoidal reference.

The output signal of the hysteresis comparator takes 0 when the average value of the primary current (switch current) becomes equal to the sinusoidal reference. In other cases, this output signal equals 0 . Note that in the flyback test bench, an LF412 operational amplifier is used.

The switch $\mathrm{S}$ is controlled by the output $\mathrm{Q}$ of the RS circuit,

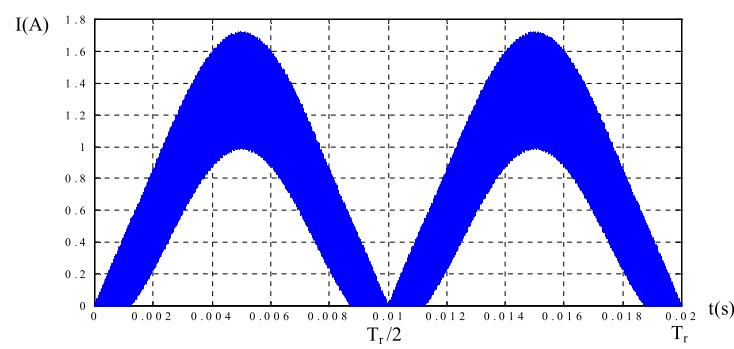

Fig. 11. The magnetic current in mixed conduction

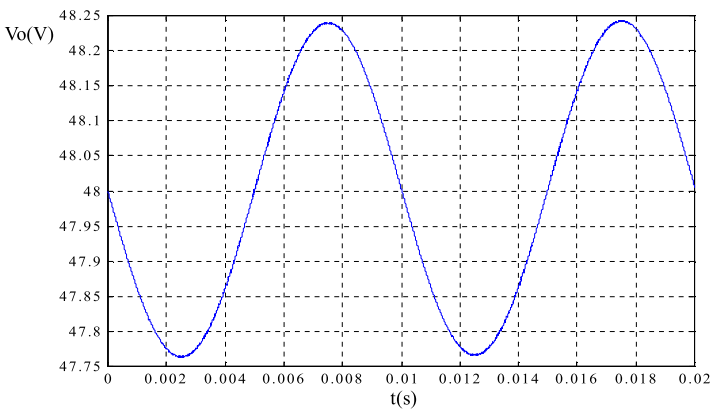

Fig. 12. The output voltage

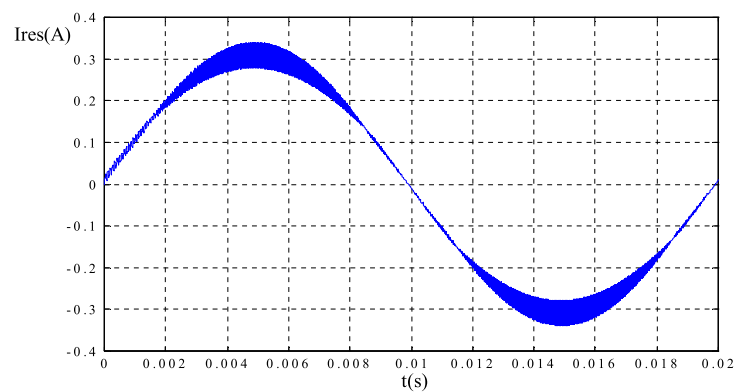

Fig. 13. The input current

the complementary output allows to reinitialize the integrator (short-circuit the integrator as soon as its output reaches zero).

The oscillator circuit allows to fix the switching frequency.

\section{A. Simulation results in mixed conduction}

The previous control strategy is adopted to control the flaback in mixed conduction. Moreover the magnetic inductance is chosen higher than the limit value ensuring discontinuous conduction over the whole low frequency period.

Figures 11 and 12 show the magnetic current and the output voltage evolutions simulated with the following parameters: $\mathrm{F}_{\mathrm{s}}=50 \mathrm{kHz}, \mathrm{m}=0.5, \mathrm{P}_{\mathrm{o}}=50 \mathrm{~W}, \mathrm{~V}_{\mathrm{o}}=48 \mathrm{~V}, \mathrm{~L}_{\mathrm{m}}=$ $2 \mathrm{mH}, \mathrm{C}=7 \mathrm{mF}$.

According to the magnetic current waveform, we note that the conduction is discontinuous around $0, \mathrm{~T}_{\mathrm{r}} / 2$ and $\mathrm{T}_{\mathrm{r}}$ (remember that $T_{r}$ is the AC voltage network period) while on the remainder of the low frequency period, the conduction is continuous.

The output voltage oscillates around the envisaged value $(48 \mathrm{~V})$, with $1 \%$ ripple.

Figure 13 shows the obtained input current filtered with the same filter used in discontinuous conduction.

We deduce that PFC operation mode is also ensured in mixed conduction. 


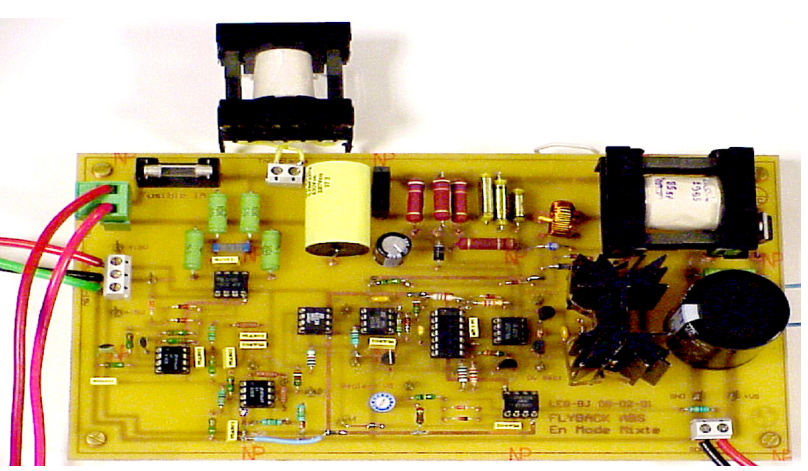

Fig. 14. The measurement workbench in mixed conduction (output power $50 \mathrm{~W}$ )

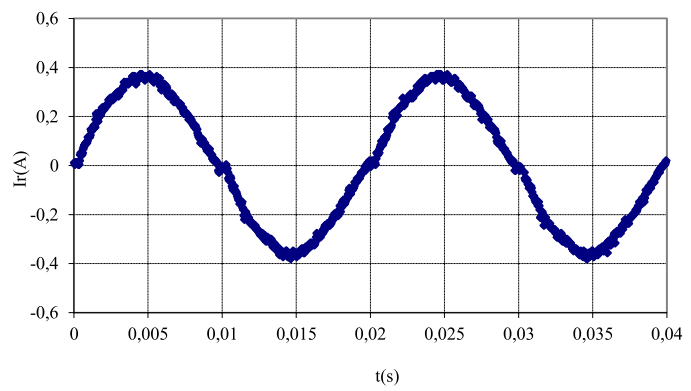

Fig. 15. Input current measurement

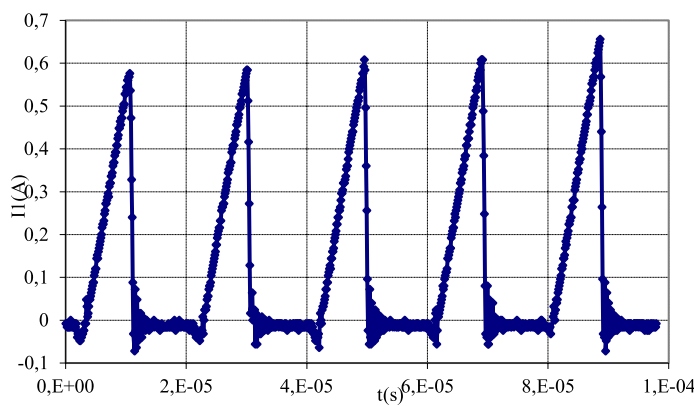

Fig. 16. Primary current measured around zero

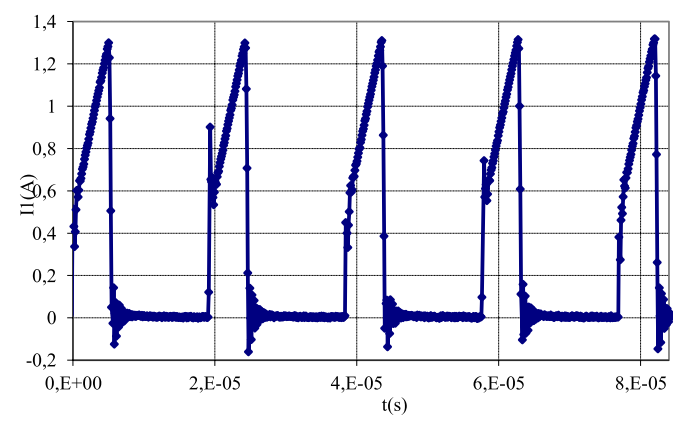

Fig. 17. Primary current measured around $\mathrm{T}_{\mathrm{r}} / 4$

\section{B. Measurement results in discontinuous conduction}

To validate the simulation results, a workbench of the flyback structure in mixed conduction is carried out (figure 14).

According to figure 15 bellow, we deduce that the measured input current is sinusoidal.

The primary current waveforms around zero (figure 16) and around $\mathrm{T}_{\mathrm{r}} / 4$ (figure 17) confirm that the two conduction modes discontinuous and continuous appear over the low frequency period.

Note that the discontinuous conduction is obtained at low

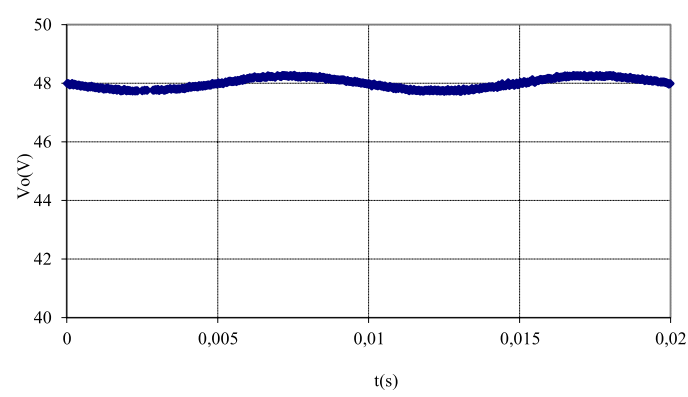

Fig. 18. Output voltage measurement

network voltage values. However, the conduction becomes continuous around $\mathrm{T}_{\mathrm{r}} / 4$ where the network voltage reaches its maximal values $\left(\mathrm{V}_{\text {res }}(\mathrm{t})\right.$ reaches $\left.\mathrm{V}_{\max }\right)$.

Figure 18 shows the output voltage measurement.

As expected, the measured output voltage oscillates around $48 \mathrm{~V}$ with $1 \%$ ripple.

These results validate the adopted control strategy allowing operation in mixed conduction.

\section{Influence of the Conduction Mode on the Con- verter Design}

The mixed conduction has been integrated into a design approach to optimize the flyback converter under multi-physic constraints (volume, efficiency, thermal and electromagnetic compatibility (EMC)). This approach is detailed in Ref. (11).

In this paper we focus only on the interaction between the mixed conduction control and volume, EMC and efficiency constraints. In this way, these constraints have been integrated progressively.

5.1 Analytical Modeling to be Used in an Optimization Process Analytical models related to the considered constraints are developed in order to carry out the optimization approach.

\section{A. Duty cycle analytical model}

According to the functional analysis of the flyback converter in discontinuous and continuous operation modes (section 3), analytical models of the duty cycle in discontinuous part and continuous part of a mixed conduction mode over a low frequency period can be deduced.

In fact, from equation 11 we deduce that the duty cycle in discontinuous conduction $\alpha_{\mathrm{dc}}$ is fixed and has the following expression:

$$
\alpha_{d c}=\frac{2}{V_{\max }} \cdot \sqrt{L_{1} \cdot F_{s} \cdot P_{o}} .
$$

Moreover, the variations of the duty cycle in continuous conduction $\alpha_{\mathrm{cc}}(\mathrm{t})$ are deduced from (8) and (9):

$$
\alpha_{c c}(t)=\frac{V_{o}}{V_{o}+m \cdot V_{\text {max }} \cdot\left|\sin \left(2 \cdot \pi \cdot F_{r} \cdot t\right)\right|}
$$

These analytical expressions have been compared to a curve obtained by simulation (figure 19) using the following parameters: $\mathrm{F}_{\mathrm{s}}=50 \mathrm{kHz}, \mathrm{L}_{1}=2 \mathrm{mH}, \mathrm{m}=0.5, \mathrm{~L}_{\mathrm{f}}=2 \mathrm{mH}$ and $\mathrm{C}_{\mathrm{f}}=0.1 \mu \mathrm{F}$. This figure shows that the duty cycle is well estimated.

In this figure the conduction is continuous between $t_{1}$ and $t_{2}$, while it's discontinuous otherwise.

The passage from the discontinuous conduction to the continuous one is carried out at $t_{1}$ which can be deduced from 


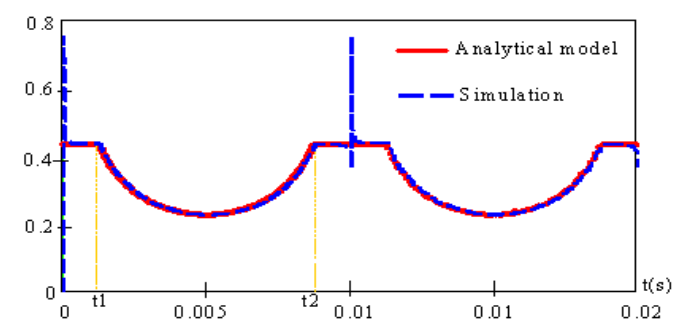

Fig. 19. Duty cycle: simulated and analytically estimated

(15) and (16): $\alpha_{\mathrm{cc}}\left(\mathrm{t}_{1}\right)=\alpha_{\mathrm{dc}}$. It yields:

$$
t_{1}=\frac{1}{2 \cdot \pi \cdot F_{r}} \cdot \arcsin \left(\frac{V_{o} \cdot\left(1-\alpha_{c d}\right)}{\alpha_{c d} \cdot m \cdot V_{\max }}\right) \ldots \ldots \ldots
$$

$t_{2}$ is deduced from $t_{1}$ by symmetry (18):

$$
t_{2}=\frac{1}{2 \cdot F_{r}}-t_{1} \cdots
$$

\section{B. Volume model}

The volume of a magnetic component (inductor or transformer) can be calculated using the effective area $\left(\mathrm{S}_{\mathrm{f}}\right)$ and the winding area $\left(S_{b}\right)(19)^{(11)}$.

$$
\text { Vol }=K_{v} \cdot\left[S_{f} \cdot S_{b}\right]^{\frac{3}{4}}
$$

$\mathrm{k}_{\mathrm{v}}$ is a volume coefficient which depends on the magnetic circuit shape.

This volume depends on electric variables: max and RMS currents, technological parameters: max flux density and current density and geometrical parameters like the winding coefficient which is the ratio of the winding and the copper areas.

Moreover, from the manufacturer datasheets, a capacitor volume can be estimated as a function of the capacitance and the capacitor voltage.

\section{Electromagnetic compatibility (EMC) model}

The adopted EMC model takes into account EMC disturbance sources (semiconductors), propagation ways of these disturbances (conductors and parasitic elements) and victims (power sources or/and loads). In order to develop simplified EMC analytical model, we suppose that the EMC disturbance can be decomposed into a differential mode (DM) and a common mode (CM). The DM disturbances use the same propagation ways as the current. However, the CM disturbances are propagated through power conductors and parasitic components as shown in figure 20. In this figure, a line impedance stabiliser network (LISN) is introduced which allows to measure the EMC disturbances.

Equivalents current and voltage sources are first calculated. Then, the spectrum of the equivalent current source is considered as a differential mode (DM) disturbance generator. The spectrum of the equivalent voltage source is considered as a common mode (CM) disturbance generator. From the equivalent diagram in each EMC mode, the EMC disturbances can be analytically estimated.

Figure 21 shows an example of the calculated and the simulated EMC differential disturbances of the flyback converter. The maximal error between the simulation and the analytical calculation in this case is $10 \%$.

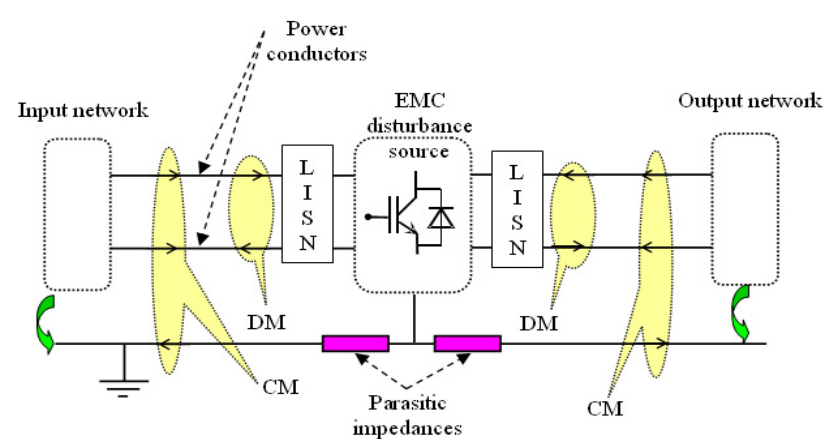

Fig. 20. DM and CM EMC disturbances

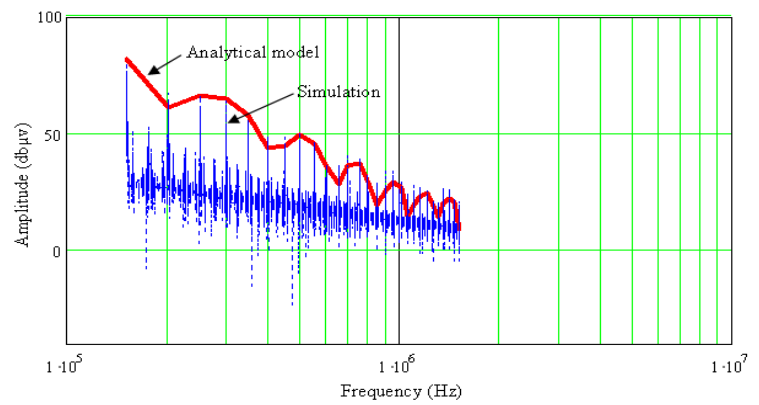

Fig. 21. EMC disturbances calculated and simulated (RMS input voltage: $230 \mathrm{~V}, \mathrm{~V}_{\mathrm{o}}=48 \mathrm{~V}, \mathrm{P}_{\mathrm{o}}=50 \mathrm{~W}, \mathrm{~F}_{\mathrm{s}}$ $\left.=50 \mathrm{kHz}, \mathrm{L}_{\mathrm{f}}=2 \mathrm{mH}, \mathrm{C}_{\mathrm{f}}=0.2 \mu \mathrm{F}\right)$

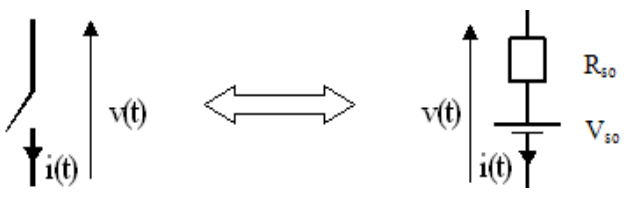

Fig. 22. A semiconductor in conduction state

The main parameters of this EMC model are the switching frequency, the inductance and the capacitance of the input filter, the primary inductor, the transformation ration and the winding maximal current. The aim of the optimization is to determine the values of these parameters allowing respecting the EMC constraint. Note that the considered parasitic parameters in the differential mode are the resistance $\left(\mathrm{R}_{\mathrm{fo}}\right)$ and the inductance $\left(\mathrm{L}_{\mathrm{fo}}\right)$ of the input filter capacitor.).

D. Semiconductors loss models

The conduction losses in a semiconductor can be evaluated using the following model:

From this model, an analytical expression of the conduction losses $\left(\mathrm{P}_{\mathrm{c}}\right)$ is deduced:

$$
P_{c}=V_{s o} \cdot I_{a v}+R_{s o} \cdot I_{r m s}^{2}
$$

$\mathrm{R}_{\mathrm{so}}$ and $\mathrm{V}_{\text {so }}$ being, respectively, the dynamic resistance and the voltage drop of the semiconductor in the conduction state.

$\mathrm{I}_{\mathrm{av}}, \mathrm{I}_{\mathrm{rms}}$ are the average and the RMS semiconductor current.

The switching losses on a high frequency period can be first estimated using the switching model shown in figure 23 and then adapted to the low frequency period ${ }^{(11)}$.

From this model, the switching-on losses of the diode can be neglected (switching-on at zero current and zero voltage). Moreover, the following switching losses relations are used:

$$
P_{s_{-} \text {on }}=\frac{1}{2} \cdot V_{\text {smax }} \cdot\left(I_{\text {smax }}+I_{r m}\right) \cdot T_{s_{-} \text {on }} \cdot F_{s} \ldots \cdots
$$




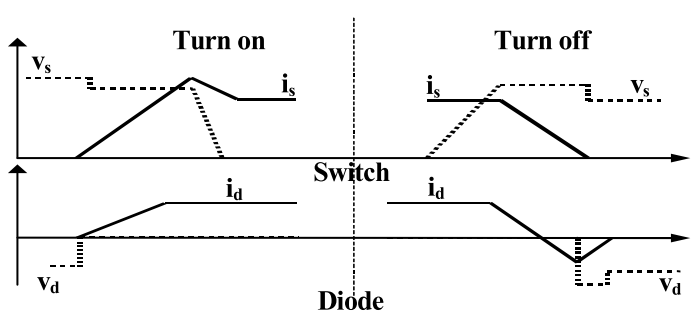

Fig. 23. Current and voltage waveforms during switching state of a switch-diode cell

$$
\begin{aligned}
& P_{s_{-} o f f}=\frac{1}{2} \cdot V_{\text {smax }} \cdot I_{\text {smax }} \cdot T_{s_{-} o f f} \cdot F_{s} \ldots \ldots \ldots \ldots \\
& P_{d_{-} \text {off }}=\frac{1}{2} \cdot V_{d \max } \cdot I_{r m} \cdot T_{d_{-} o f f} \cdot F_{s} \ldots \ldots \ldots \ldots \cdots
\end{aligned}
$$

$\mathrm{P}_{\mathrm{S}_{-} \text {on }}$ and $\mathrm{P}_{\mathrm{S}_{-} \text {off }}$ are the switching-on and the switching-off losses in the switch,

$\mathrm{P}_{\mathrm{d}_{\text {_off }}}$ is the diode switching-off losses,

$\mathrm{V}_{\mathrm{smax}}$ and $\mathrm{V}_{\mathrm{dmax}}$ are the max voltages of the switch and the diode,

$\mathrm{I}_{\mathrm{smax}}$ and $\mathrm{I}_{\mathrm{rm}}$ are the max current in the switch and the recovery current of diode,

$\mathrm{T}_{\mathrm{S}_{-} \text {on }}, \mathrm{T}_{\mathrm{S}_{\text {_off }}}$ and $\mathrm{T}_{\mathrm{d} \_ \text {off }}$ are the semiconductor switching times.

5.2 Optimization Procedure The design has been made by using the previous analytical models in an optimization process. This optimization has been carried out thanks to a specific optimization tool (Pro@Design) ${ }^{(20)(21)}$ with a deterministic gradient algorithm to carryout compromise between the computing time and the results accuracy.

In the flyback converter, the objective function to be minimized is the passive elements volume (sum of input filter and transformer volumes) and the main constraints to be respected are EMC and efficiency (active components losses). The main optimization parameters are the switching frequency $\left(\mathrm{F}_{\mathrm{s}}\right)$, the primary inductance $\left(\mathrm{L}_{1}\right)$, the transformation ratio of the transformer $(\mathrm{m})$, the inductance $\left(\mathrm{L}_{\mathrm{f}}\right)$ and the capacitance $\left(\mathrm{C}_{\mathrm{f}}\right)$ of the input filter. In addition, the duty cycle $(\alpha)$ is considered, in this paper, as a key optimization parameter in order to optimize the balance between the discontinuous and continuous conductions over the low frequency period while respecting EMC and efficiency constraints. In this way, $t_{1}$ (figure 19) is constrained between $0.5 \mathrm{~s}$ and $4.5 \mathrm{~s}$ (it means that discontinuous conduction duration is constrained between $1 \mathrm{~s}$ and $9 \mathrm{~s}$ over $10 \mathrm{~s}$ low frequency period).

5.3 Optimization Results Remember that in this part we focus only on the interaction between the mixed conduction control and the EMC and efficiency constraints. To do so, these two constraints are integrated progressively. The observed optimization parameter is the duty cycle $(\alpha)$ which is the image of the mixed control strategy (in this part, the switching frequency is fixed to $80 \mathrm{kHz}$ ).

\section{A. Volume optimization under EMC constraint}

In this section we aim to optimize the duty cycle by minimizing the passive components volume and by respecting the ISM 55011 EMC standard (which imposes that EMC disturbances induces by the converter must be lower or equal $79 \mathrm{db} \cdot \mu \mathrm{V})$.

Figure 24 shows the variations versus time of the optimized duty cycle with volume and EMC considerations:

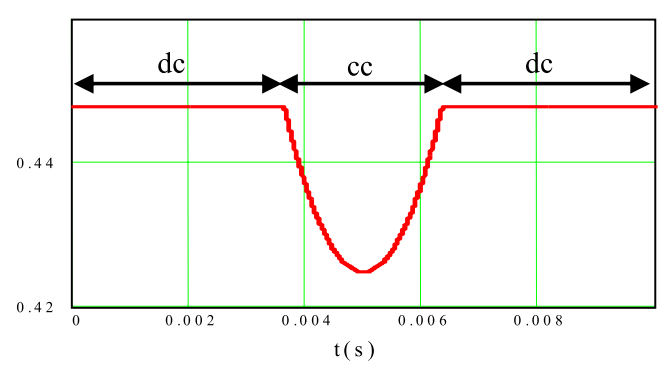

Fig. 24. Optimized duty cycle when minimizing volume and respecting EMC constraint

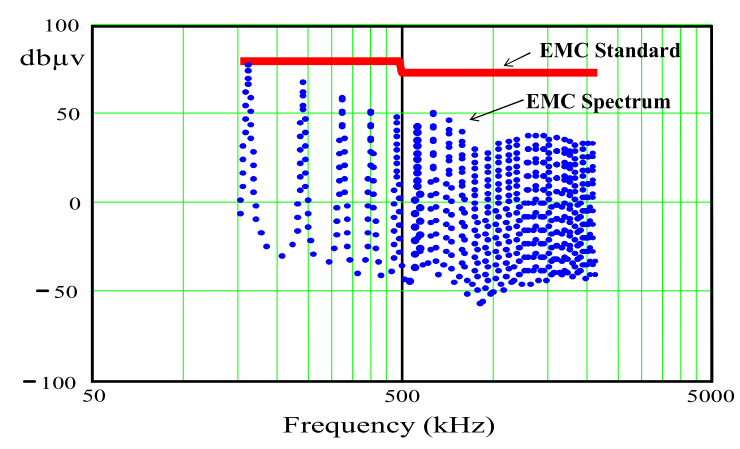

Fig. 25. Obtained EMC spectrum compared to the standard limitation

We deduce that the discontinuous conduction (dc) duration $(2 \cdot \mathrm{t} 1=7.3 \mathrm{~s}$ over $10 \mathrm{~s}$ low frequency period $)$ is about 3 times the continuous conduction (cc) duration. In this case, maximal and RMS currents are not constrained throw losses or efficiency. So as it can be predicted from section 3, the optimization process has favored the discontinuous conduction to minimize the passive components volume as a major criterion. The obtained volume in this case is $25.3 \mathrm{~cm}^{3}$. Remember that this volume represents the sum of transformer and input filter volumes.

Figure 25 presents the corresponding EMC spectrum (according to frequency) compared to the considered standard.

According to this figure we can check that the EMC constraint is respected.

Note that the annoying harmonics are located at frequencies multiples of the switching frequency. Knowing that the switching frequency is $80 \mathrm{kHz}$ fixed in our case, the first important harmonic (amplitude $79 \mathrm{db} \cdot \mu \mathrm{V}$ ) is located at the frequency $160 \mathrm{kHz}$ (figure 25). It means that the input filter is mainly designed to respect the EMC standard at this frequency.

B. Volume optimization under EMC and efficiency constraints

In addition to the EMC ISM 55011 standard to be respected, The aim now is to optimize the duty cycle by minimizing the passive components volume and respecting a constraint related to the converter efficiency which must be higher or equals $93 \%$.

Figure 26 shows the optimized duty cycle considering volume EMC and efficiency constraints:

In this case, the efficiency constraint effect is more significant than the volume minimization. Consequently, the continuous conduction is preferred than the discontinuous one (continuous conduction duration $8 \mathrm{~s}$ over $10 \mathrm{~s}$ low frequency 


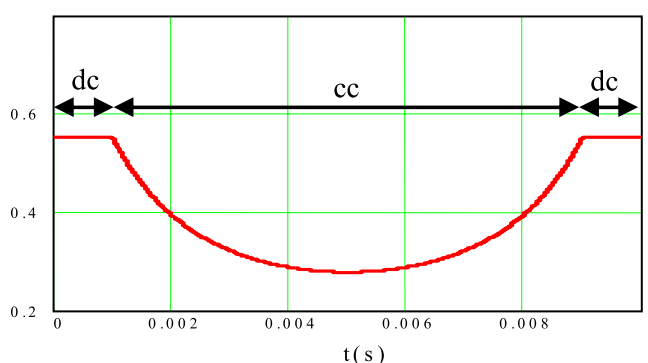

Fig. 26. Optimized duty cycle when minimizing volume and respecting EMC and efficiency constraints

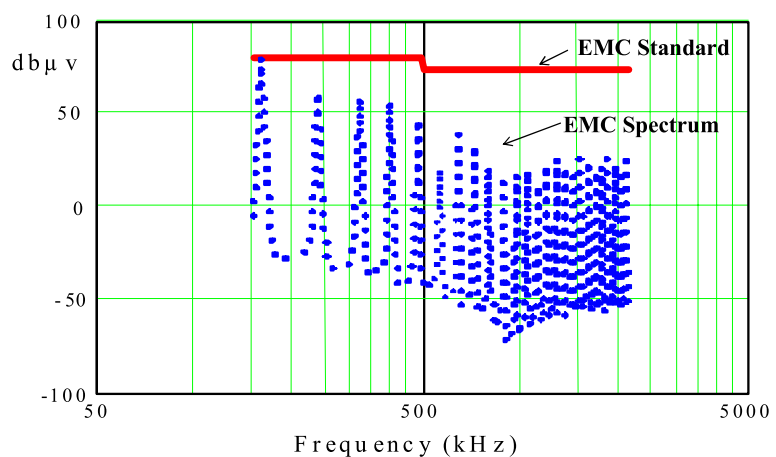

Fig. 27. Optimized EMC spectrum compared to a standard limitation

period) to constrain RMS, maximal and mean current values impacting semiconductor losses.

The obtained efficiency is $94 \%$ which respects the efficiency constraint. The optimized volume in this case is $42.3 \mathrm{~cm}^{3}$ which is more important than the volume obtained in the previous case (where only EMC was constrained). As expected, constraining efficiency impact current values and consequently increases the flyback transformer volume.

Moreover, the EMC spectrum amplitudes are lower than those imposed by the considered EMC standard (figure 27).

Note that in both cases (volume optimization under EMC constraint, volume optimization under EMC and efficiency constraints), the duty cycle has been adjusted by optimization to respect the imposed constraints while minimizing passive components volume. The optimization process allowed to deduce automatically the suitable balance between discontinuous and continuous conduction durations over the low frequency period in order to respect specifications which is very helpful to designer. These results confirm the strong impact of the control aspect, determining the current conduction mode, on the converter design and show the interest to consider the conduction mode as an optimization criterion.

\section{Conclusion}

A control study and its impact on the design of a PFC flyback converter are presented in this paper.

An analysis in discontinuous and continuous conductions allowed to deduce that from the point of view design, continuous conduction over the whole low frequency period is not interesting because it induces a very high transformer volume. For this reason, the continuous conduction over all the low frequency period was excluded and control strategies associated to discontinuous conduction and mixed conduction are simulated and validated by measurements.
The most interesting conduction (the mixed one combining both discontinuous and continuous conductions over the low frequency period and allowing compromise between volume and semiconductor's current constraints) is integrated within an optimization process in order to determine automatically suitable duration of each conduction mode allowing respecting imposed constraints. It was shown that the optimization process favors the continuous conduction duration when the efficiency is the most significant constraint. However, the discontinuous conduction duration is more important when the most significant constraint is the passive components volume.

\section{References}

( 1 ) F. Forest, E. Laboure, B. Gelis, V. Smet, T.A. Meynard, and J.J. Huselstein: "Design of Intercell Transformers for High-Power Multicell Interleaved Flyback Converter", IEEE Trans. Power Electronics, Vol.24, No.3, pp.580-591 (2009)

( 2 ) M. Hao, J. Yue, and X. Ye: "Design and Analysis of Single-Stage Power Factor Correction Converter With a Feedback Winding”, IEEE Trans. Power Electronics, Vol.25, No.6, pp.1460-1470 (2010)

( 3 ) C. Larouci, J.P. Ferrieux, L. Gerbaud, J. Roudet, and J. Barbaroux: "Control of a flyback converter in Power Factor Correction mode: compromise between the current constraints and the transformer volume", IEEE Applied Power Electronics Conference APEC'02, pp.722-727 (2002)

( 4 ) H. Bai, Z. Nie, and C.C. Mi: "A model-based dead-band compensation for the dual-active-bridge isolated bidirectional DC-DC converter", IEEJ Transactions on Electrical and Electronic Engineering, Vol.6, No.6, pp.517-524 (2011)

( 5 ) A.Ch. Kyritsis, N.P. Papanikolaou, E.C. Tatakis, and J.L. Kobougias: "Design and control of a current source flyback inverter for decentralized gridconnected photovoltaic systems", European Conference on Power Electronics and Applications EPE'05, pp.5045-5048 (2011)

( 6 ) D.G. Lamar, A. Fernandez, M. Arias, M. Rodriguez, J. Sebastian, and M.M. Hernando: "Limitations of the Flyback Power Factor Corrector as a OneStage Power Supply”, IEEE PESC'07, pp.1343-1348 (2007)

( 7 ) C. Jiamin, Y. Xianfeng, W. Ling, X. Weijie, Q. Huibin, and S. Lihuan: "The control-loop design of quasi-resonant flyback converter for HI-bright LED driver", International Conference on Electrical and Control Engineering ICECE'11, pp.1343-1348 (2007)

( 8 ) J.-H. Jung and S. Ahmed: "Flyback converter with novel active clamp control and secondary side post regulator for low standby power consumption under high-efficiency operation", IET Power Electronics, Vol.4, No.9, pp.10581067 (2011)

( 9 ) Y. Kusuhara, A. Nakayama, T. Ninomiya, and S. Nakagawa: "Power Flow Control for Efficiency Improvement in a Forward-Flyback Mixed Converter", International Conference on Power Electronics and Drive Systems PEDS'07, pp.749-753 (2007)

(10) L. Yong and J. Zheng: "A low-cost adaptive multi-mode digital control solution maximizing AC/DC power supply efficiency", IEEE APEC'10, pp.349354 (2010)

(11) C. Larouci, C.M. Boukhnifer, and A. Chaibet: "Design of Power Converters by Optimization Under Multi-physic Constraints; Application to a Two-Time Scales AC/DC-DC Converter", IEEE Transactions on Industrial Electronics, Vol.57, No.11, pp.3746-3753 (2010)

(12) H.-J. Chiu, Y.-K. Lo, H.-C. Lee, S.-J. Cheng, Y.-C. Yan, C.-Y. Lin, T.-H. Wang, and S.-C. Mou: "A Single-Stage Soft-Switching Flyback Converter for Power-Factor-Correction Applications", IEEE Trans. on Industrial Electronics, Vol.57, No.6, pp.2187-2190 (2010)

(13) J. Zhang, L. D.D.-C, and T. Sun: "Flyback-Based Single-Stage Power-FactorCorrection Scheme With Time-Multiplexing Control", IEEE Trans. on Industrial Electronics, Vol.57, No.3, pp.1041-1049 (2010)

(14) F. Zhang and C. Gong: "A New Control Strategy of Single-Stage Flyback Inverter", IEEE Trans. on Industrial Electronics, Vol.56, No.8, pp.3169-3173 (2009)

(15) B. Tamyurek and D.A. Torrey: "A Three-Phase Unity Power Factor SingleStage AC-DC Converter Based on an Interleaved Flyback Topology", IEEE Trans. on Power Electronics, Vol.26, No.1, pp.308-318 (2011)

(16) H.S. Athab and D.D.-C Lu: "A High-Efficiency AC/DC Converter With Quasi-Active Power Factor Correction", IEEE Trans. on Power Electronics, Vol.25, No.5, pp.1103-1109 (2010) 
(17) Y.-C. Chuang, Y.-L. Ke, H.-S. Chuang, and C.-C. Hu: "Single-Stage PowerFactor-Correction Circuit with Flyback Converter to Drive LEDs for Lighting Applications", IEEE Industry Applications Society IAS'10, pp.1-9 (2010)

(18) K.S. Hee, M. Dragan, and C. Isaac: "On-line efficiency optimization in flyback dc-dc converters over wide ranges of operating conditions", IEEE Applied Power Electronics Conference APEC'11, pp.1417-1424 (2011)

(19) T. Bhattacharya, V.S. Giri, K. Mathew, and L. Umanand: "Multiphase Bidirectional Flyback Converter Topology for Hybrid Electric Vehicles", IEEE Transactions on Industrial Electronics, Vol.56, No.1, pp.78-84 (2009)

(20) E.Atienza, J. Bigeon, F. Wurtz, and B. Belhabib: "Steps to an Electrical Design Environment", IEEE-IECON'99, San Jose, CA,USA, November 29thDecember 3rd, pp.815-820 (1999)

(21) R.J. Pasterczyk, J.-M. Guichon, J.-L. Schanen, and E. Atienza: "PWM Inverter Output Filter Cost-to-Losses Tradeoff and Optimal Design”, IEEE Transactions on Industry Applications, Vol.45, No.2, pp.887-897 (2009)

Cherif Larouci (Non-member) received a $\mathrm{PhD}$ in electrical engi-

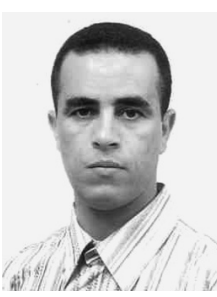
neering from the "Institut National Polytechnique de Grenoble", France, in 2002. He is currently a research professor with the Control and System laboratory, ESTACA engineering school, France. His research interests include design of power electronic applications for automotive, aeronautics and railway industries.
Ahmed Chaibet (Non-member) obtained a $\mathrm{PhD}$ in Automatics from

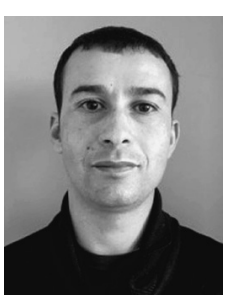
University of Evry Val-d'Essonne, France, in June 2006. He joined the Control and System laboratory of ESTACA engineering school in May 2007. His research includes robust control of electrical machines.

Moussa Boukhnifer (Non-member) is research professor in the Con-

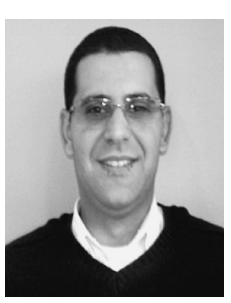
trol and System laboratory of ESTACA engineering school. In December 2005, he received a PhD in Control and Engineering from the University of Orléans, France. His main research interests are focused on the design, modeling, control and optimization with its applications to power electronics and electrical drives.

Toufik Azib (Non-member) received a Ph.D. in electrical engineer-

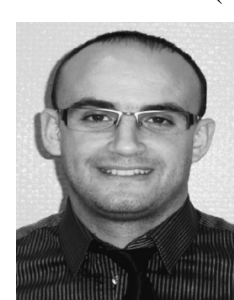
ing from the University of Paris South XI, France, in 2010. Since 2011, he has been an Associate Professor with the Control and System laboratory, ESTACA engineering school, France. His current research interests include power electronics, and new electrical devices (Fuel cell, batteries and ultracapacitors). 